action was the most probable cause that took place in the treatment of this case (13).

Admixture of SM to hyperosmolar dextrose solution in concentrations of 1:10, 1:7, 1:5, and 1:2 has been used for many years by sclero/prolotherapists. There have never been any reports describing successful administration of $1 \% \mathrm{SM}$ in $15 \%$ dextrose to cure a synovial cyst (13).

Potentially sclerotherapy may be applicable to treat many other symptomatic cysts within musculoskeletal system.

Zygapophyseal joints cysts are a common painful entity found on the MRI and anteriorly located cysts often communicate with the joint cavity. The Interventional Pain Management community is well trained for needle placements into these joints. Perhaps, the treatment modality discussed here, may be worthwhile studying in efforts to evaluate whether it has the potential to offer a curative response for such problems.

Felix Linetsky, MD

Orthopaedic Medicine Pain Treatment

36472 US $19 \mathrm{~N}$

Palm Harbor, FL 34684

prolopain@aol.com

\section{References}

1. Centeno C J, Schultz J, Freeman $M$. Sclerotherapy of Baker's Cyst with imaging confirmation of Resolution. Pain Physician 2008; 11:257-261.

2. Hoch G. Injection treatment of hydrocele. In F. Yeomans (ed.), Sclerosing Therapy, the Injection Treatment of Hernia, Hydrocele, Varicose Veins and Hemorrhoids p. $141-156$. Bailliere, Tindall \& Cox. London, 1939 .

3. Linetsky FS. History of sclerotherapy in urology. The Pain Clinic 1999; 5:30-32.

4. Higgins T, Kittel P. Injection treatment with sodium morrhuate. Lancet 1930 ; i:68-69,

5. Poritt A. The injection Treatment of Hy- drocele, Varicoceles, Bursae and Nevi. Proceedings, Royal Society of Medicine, 10. Watson, L. Hernia (2nd ed.). C.V. Mosby 24, 81. 1931.

6. Biegeleisen $H$. Varicose veins, related diseases and sclerotherapy: A guide for practitioners. Eden Press, Montreal, 1984 .

7. Ewell et al. Hydrocele operative and injection treatment. Wisconsin M.J.34: 451-456, 1935.

8. Schultz $L A$. treatment for subluxation of the temporomandibular joint. JAMA 1937; 13;1032 -1034, .

9. Warren J. Hernia-Sstrangulated and Reducible with Cure by Subcutaneous Injection. Charles C Thomas: Boston,
1881. St. Louis, 1938.

11. Yeomans F. Sclerosing Therapy, The Injection Treatment of Hernia, Hydrocele, Varicose Veins and Hemorrhoids. Bailliere, Tindall \& Cox. London, 1939.

12. Riddle, P. Injection Treatment. Philadelphia: W. B. Saunders 1940.

13. Linetsky F, Eek B, Derb R, Paris WCV. Regenerative Injective Therapy, Chapter 35 in Low Back Pain: Diagnosis and Treatment, Manchikanti, Slipman, Fellows, (eds). ASIPP Publishing, Paducah, KY. 2002: pp. 519-540.

\title{
Anatomy, Imaging, Treatment Options for Baker's Cyst
}

\section{TO THE EDITOR:}

We read with interest the case report by Centeno et al (1) describing "Sclerotherapy of Baker's Cyst with Imaging Confirmation of Resolution." We wish to comment on aspects relating to the anatomy, imaging, and treatment options.

Adams (2) originally described the popliteal cyst in 1840 and in 1877 Baker (3) detailed it further as being caused by trapping of fluid in a bursa related to the semimembranosus tendon.

A Baker's cyst is a synovial cyst that usually communicates with the knee joint by way of a slit-like opening, lined with synovium. Rausching and Lindgren (4) in their study suggested 2 mechanisms for cyst formation. The primary cyst has an unilateral valvular connection and the secondary cyst communicates freely with the knee joint and contains synovial fluid of normal viscosity. Intrinsic intraarticular disorders causing excessive joint effusion and cyst may serve as a protective mechanism by reducing destructive pressure in the joint space (5).

Centeno et al (1) describe a large Baker's cyst that freely communicates with the knee joint based on MRI imaging. However the benefit of using MRI is the ability to use the axial plane images to establish positive identification of high signal intensity, at the fluid filled neck of the cyst that connects to the joint 
space (6). The article shows a series of MRI images, all of them being sagittal views, which fails to reveal cyst communication with the knee joint.

Centeno et al (1) reported the use of prolotherapy in a 56-year-old male with a large Baker's cyst which had been treated conservatively including multiple simple aspirations which were unsuccessful. However, the mechanism of cyst resolution remains unexplained.

Prolotherapy is a derivation of proliferative injection therapy and also vaguely known as sclerotherapy. We question whether the resolution of the cyst is due to the natural healing effect of prolotherapy agents on injured menisci, strengthening of ligaments or sclerosing effect on the synovium. In current literature, there is conflicting evidence regarding the efficacy of prolotherapy. Furthermore, even after surgical excision of the cyst, recurrence of Baker's cyst has been reported if the underlying cause was not addressed $(7,8)$.

We agree with Centeno et al (1) that this is an isolated case report but could not conclude that prolotherapy is a reasonable treatment option.

Sridhar Pinnamaneni, MD
Interventional Pain Management Fellow
Department of Anesthesiology
SUNY Upstate Medical University
Syracuse, NY
E-mail: painmed@yahoo.com
P. Sebastian Thomas, MD
Professor of Anesthesiology
Program Director, Pain Fellowship
SUNY Upstate Medical University

\section{References}

1. Centeno CJ, Schultz J, Freeman $\mathrm{M}$. Sclerotherapy of Baker's cyst with imaging confirmation of resolution. Pain Physician 2008; 11:257-261

2. Adams R. Arthritis, Chronic rheumatica, of the knee joint, Dublin J Med Sci 1840; 17:520-523.

3. Baker WM. On the formation of synovial cysts in the leg in connection with disease of the knee joint. St Bartholomew's
Hospital Reports 1877; 13: $45-261$.

4. Rauschning W, Lindgren PG. The clinical significance of the valve mechanism in common popliteal cysts. Arch Orthop Trauma Surg 1979; 95:251- 256.

5. Fritschy D, Fasel J, Imbert Jc, Bianchi S, Verdonk R, Wirth CJ. The Popliteal cyst. Knee Surg Sports Traumatol Arthros, 2006; 14:623-628

6. Sansone V, De Ponti A, Paluello GM.
Popliteal cysts and associated disorders of the knee. Critical review with MR imaging. Int Orthop 1995; 19:275-279.

7. Handy JR. Popliteal cysts in adults: A review. Seminoars in Arth and Rhem. 2001; 31:108 -118.

8. Stefan R, Romain S, Petra J, Kohn D. Popliteal cysts in adults. Am J Sport Med 2002; 30:112- 115.

\section{In Response}

We appreciate the timely and thoughtful letter submitted by Pinnamaneni and Thomas. This group is concerned that we have not provided evidence that we have in fact treated a true Baker's cyst that communicates with the joint capsule. The initial MRI report from 4/06 does confirm that the reading musculoskeletal radiologist made this diagnosis. We have also provided the image slice below that we believe shows convincing evidence that this is a Baker's cyst.

Prolotherapy as discussed by Pinnamaneni and Thomas is the use of an injectable solution to cause tissue proliferation. However, a much simpler description is that prolotherapy is an osmolar micro injury technique. The ability of sodium morruhate to cause micro injury and thus tissue proliferation has been confirmed in tendons under electron microscopy (1). Pinnamaneni and Thomas suggest that the effects of the prolotherapy may have been to heal any internal derangement within the knee. We would agree that such a micro injury with subsequent healing may explain the results. Micro injury techniques are common in medicine. Examples include non-healing, cutane- 


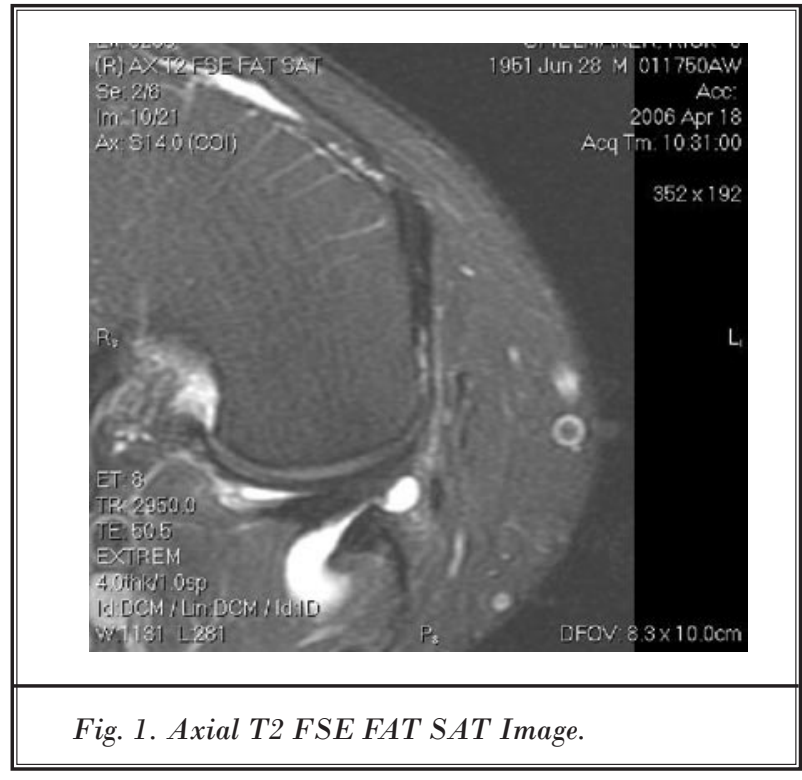

ous wound debridement, orthopedic micro fracture for OCD's, orthotripsy for chronic plantar fasciitis, and thermal capsulorrhaphy for shoulder instability. Many of these techniques work by initiating a healing response in the area. Alternatively, as we have discussed, the simple mechanism of capsular constriction via a sclerosant may also explain the result. It is well known that sodium morruhate works via this mechanism to eliminate varicose veins.

We disagree with the statement by Pinnamaneni and Thomas that prolotherapy is not a reasonable treatment option. While we acknowledge that larger placebo controlled, multicenter trials will have to confirm the efficacy of prolotherapy treatment for Baker's cyst, pain management physicians use techniques everyday which do not meet this standard. This list includes cervical epidural steroid injections, various types of RF techniques, intraarticular facet injections, and peripheral joint corticosteroid injections just to name a few. We would not advocate that pain management physicians drop these techniques from their clinical armamentarium just as we would not advocate that providers who use prolotherapy drop this technique. Perhaps Sackett (2) put it best when they said, "Good doctors use both individual clinical expertise and the best available external evidence, and neither alone is enough."

Christopher Centeno, MD

The Spinal Injury Foundation

11080 Circle Point Road, Suite 140

Westminster, CO 80020

Email: centenooffice@centenoclinic.com

\section{References}

1. Liu YK, Tipton CM, Matthes RD, Bedford TG, Maynard JA, Walmer HC. An in situ study of the influence of a sclerosing solution in rabbit medial collateral lig- aments and its junction strength. Connect Tissue Res 1983; 11:95-102.

2. Sackett DL, Rosenberg WM, Gray JA, Haynes RB, Richardson WS. Evidence based medicine: What it is and what it isn’t. BMJ 1996; 312:71-72. 